\title{
Visual Dysfunction with Basal Skull Tumours
}

\author{
James A. Sharpe
}

\begin{abstract}
Early detection of visual loss caused by tumours of the base of the skull is accomplished by systematic tests of the pregeniculate optic pathway. Even when central acuity is relatively preserved, a relative afferent pupillary defect and reduced color perception yield evidence of impaired optic nerve conduction. Although confrontation tests of the visual fields are useful screening techniques, unexplained symptoms should be pursued with static and kinetic perimetry. Patterns of optic nerve and chiasmal field loss and atrophy of the disc or retinal nerve fibers are imprecise guides to the location of basal skull tumours. Regardless of the pattern of visual field defect, unexplained progressive loss of vision demands intensive neuroradiologic study of the basal cisterns and skull.
\end{abstract}

RÉSUMÉ: Troubles visuels accompagnant les tumeurs de la base du crâne La détection précoce des troubles visuels causés par les tumeurs de la base du crâne est faite en employant une série de tests systématiques de la voie optique prégéniculéee. Même lorsque l'acuité centrale est relativement conservée, un défaut pupillaire afférent et la perception réduite des couleurs permettent d'envisager une conduction nerveuse atteinte dans le nerf optique. Les tests de confrontation du champ visuel peuvent servir d'épreuve de dépistage, mais il est important d'investiguer avec attention toute symptôme inexpliqué en se servant de la périmétrie statique et cinétique. Les atteintes du champ visuel et du nerf optique ainsi que l'atrophie de la papille optique et des nerfs rétiniens ne peuvent être considérés que comme des guides imprécis pour la localisation des tumeurs de la base du crâne. Peu importe la sorte de perte du champ visuel, toute perte progressive de la vue nécessite une investigation neuro-radiologique poussée des citernes de la base et du crâne.

Can. J. Neurol. Sci. 1985; 12:332-335

Tumours arising at the skull base degrade vision by compression of the prechiasmatic optic nerve, chiasm or tract. The common mass lesions are pituitary adenoma, meningioma, craniopharyngioma and supraclinoid aneurysm. Other invasive tumours described in this symposium are infrequent culprits. Malignant astrocytomas arising within the lower visual pathway are rarely responsible.' Occasionally, gliomas that originate within the cerebrum compress or invade the optic nerves or chiasm. ${ }^{2,3}$ Tumours that extend in front of the chiasm cause a distinctive syndrome of incipient optic nerve compression: dimming of vision with near normal Snellen acuity, poor colour perception, an afferent pupillary defect and a normal appearing optic disc. ${ }^{4}$ Surgical decompression often produces remarkably rapid recovery of vision, but delay in diagnosis results in tumour enlargement and optic atrophy with irreversible visual loss. ${ }^{5}$ Too often, the insidious visual blurring is incorrectly attributed to ocular disease such as subtle macular degeneration.

Certain practical clinical tests of optic nerve conduction are critical for early diagnosis: assessment of best corrected visual (central) acuity, colour perception with pseudoisochromatic plates, the pupillary light reflex and visual fields. The optic nerve is often not pale, even with severe and long standing compression up to two years. ${ }^{6}$ The pupillary light reflex is particularly valuable since it is the most sensitive objective sign of impaired optic nerve function ${ }^{7,8}$ even when Snellen acuity is normal and visual field loss is minor. Minor defects in conductivity of one nerve are identified when a light is swung rapidly from eye to eye. When the more affected eye is illuminated, both pupils dilate and when the better eye is illuminated both pupils constrict. This swinging light test detects a relative afferent pupil defect (RAPD), the Marcus Gunn pupillary sign. A RAPD usually signifies optic nerve disease or extensive retinal damage; it excludes subtle macular disease or opacities of the ocular media as causes of visual loss. Involvement of the chiasm causing asymmetrical field loss is associated with a RAPD in the eye with greater field loss. Optic tract damage causes a RAPD in the eye opposite the lesion since the tract contains more nasal crossed fibres than temporal uncrossed fibres. ${ }^{9}$

Visual field examinations are designed to test both central (foveal) acuity and extrafoveal "acuity". Screening confrontation tests can be performed with the examiner's fingers and hands and by comparison of desaturation of red objects presented in intact and defective areas of the field. However, static finger counting misses about $50 \%$ of hemianopic defects due to 
chiasmal disease and colour confrontation techniques miss about $20 \% .^{10}$ Such confrontation tests are too unreliable to detect mild optic nerve field defects. After chiasmal compression, false positive tests of finger confrontation (about 15\%) and colour desaturation (about $30 \%$ ) testify to the sensitivity of confrontation techniques, but false negative results indicate that quantitative perimetry with kinetic and static objects is required. The Goldmann perimeter is a universal standard of field analysis. Its use is being preempted by computer automated perimeters.

Prechiasmal compression usually causes central field defects. The intracranial optic nerve is 15 to $20 \mathrm{~mm}$ long and inclined $45^{\circ}$ from the horizontal. The optic chiasm, which comprises the crossroads of all visual traffic in 2.4 million axons, lies 8 to $13 \mathrm{~mm}$ above the diaphragma sella. Thus pituitary tumours must have considerable suprasellar extension before they compress the chiasm. " CT scanning can detect suprasellar extension well before it is manifested by visual dysfunction, and serial CT examinations should be more sensitive in detecting postoperative tumour recurrence. Anterior extension of small pituitary tumours impairs vision by involving the optic nerve long before the chiasm is compressed.

Diagramatic representations of nerve fibre projections in the human optic chiasm should not be taken literally; they are speculative, since topographic fibre organization is not precisely known. "Schematic correlations of visual field defects with sharply defined lesions are confabulatory. Tumours exert diffuse, not knife-like, compression on chiasmal axons and their vasculature. Only the observation that dysfunction of the median bar of the chiasm causes temporal field defects demar-

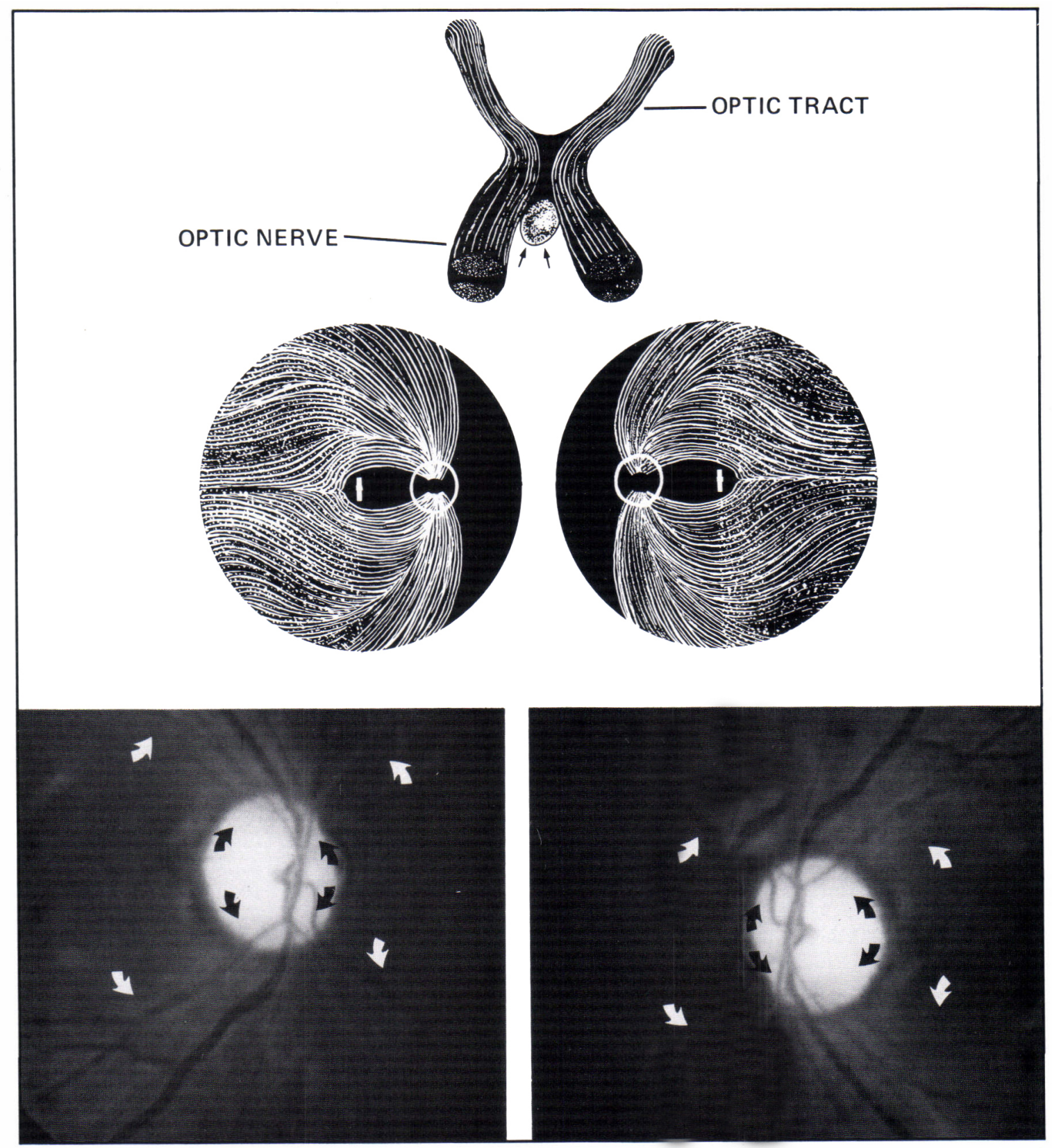

Figure I - Schema of hemioptic atrophy of nerve fibres from the nasal retinas caused by compression of the optic chiasm (adapted courtesy of Dr. W. F. Hovt), and corresponding transverse bands of disc atrophy in a 48 year old woman with a pituitary adenoma. 
cated along the vertical meridian is axiomatic. Compression affects not only the median bar but also the lateral chiasm. Subtle depression of the central and intermediate nasal field to static test objects can be identified when confrontation techniques and kinetic perimetry detect only temporal field defects. ${ }^{12}$ Macular fibres make up about $90 \%$ of the chiasm and occupy a considerable portion of its volume. Traquair's description of macular fibres forming a little chiasm toward its posterior part must be qualified; only the anteroinferior and posteroinferior chiasm seems to be free of macular axons. " Patterns of visual field loss are imprecise guides to tumour localization when compared to high resolution computed tomography and magnetic resonance imaging.

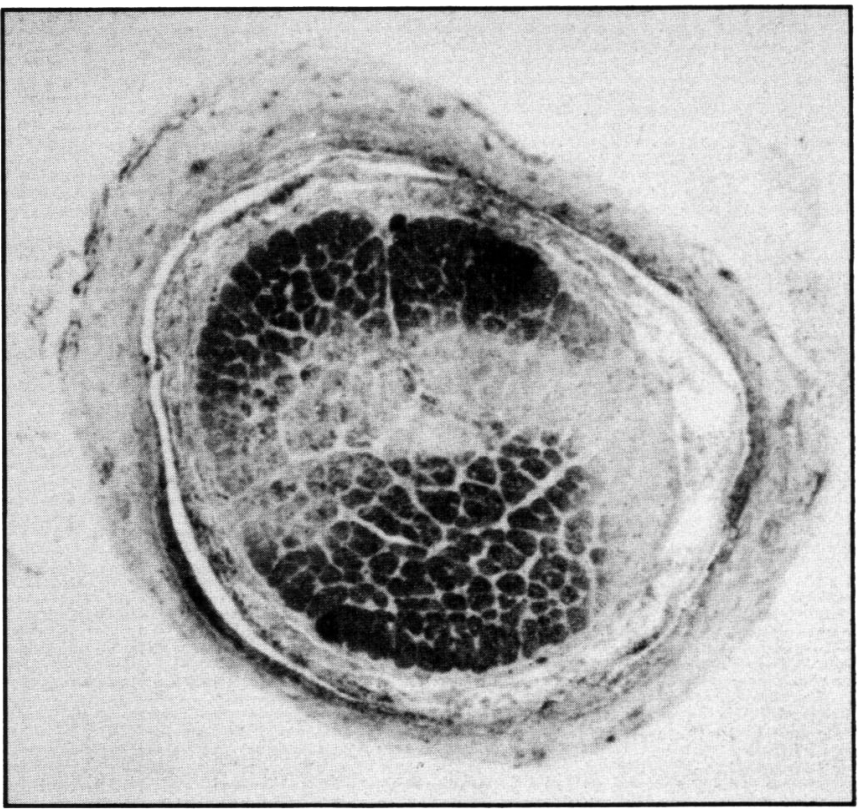

Figure 2-Myelin stain of the optic nerve several mm behind the globe after compression of the optic chiasm by tumour shows transverse band of atrophy of nerve fibres originating in the nasal retina. (Courtesy of the late Dr. Frank B. Walsh. Baltimore)
Mechanisms of loss and recovery of vision have been addressed by McDonald. ${ }^{13}$ Experimental optic nerve compression causes: 1) rapidly reversible conduction block which is attributed to ischemia; 2) selective demyelination with sparing of axons, and then remyelination even during continued compression of the optic nerve; and 3) irreversible wallerian degeneration. Nonetheless, cats with stereotactically produced optic nerve lesions recover spatial contrast sensitivity despite wallerian degeneration; ${ }^{14}$ the mechanism is unknown. Visual recovery after chiasmal decompression has a rapid component within minutes to hours, an intermediate component within days to weeks and a prolonged component of months, up to a year. ${ }^{5}$

Wasting of retinal nerve fibres and optic disc pallor are funduscopic signs of retrograde axonal degeneration. Damage to the median bar of the chiasm causes loss of nerve fibres from the nasal hemioptic retina (Figure 1) which results in transverse atrophy of the optic nerve (Figure 2), visible as a horizontal band of optic atrophy. Attrition of the retinal nerve fibre layer (NFL) may appear before disc pallor. White and Sharpe ${ }^{15}$ studied the NFL in 10 patients with chiasmal compression, using red free retinal photography before and serially from one to nine years after surgery. Degeneration of the nasal hemioptic NFL was evident in seven of twenty eyes. Seven eyes showed diffuse atrophy. Six showed a normal NFL. Field loss persisted in all 14 eyes with diffuse or hemioptic atrophy but incomplete recovery of acuity or fields occurred in three of fourteen such eyes. All six eyes without visible NFL atrophy showed total or near total resolution of visual loss. The appearance of the NFL within a few weeks of surgery has little prognostic significance since surgical damage may cause axonal disruption that takes several weeks to appear as NFL loss in the retina. ${ }^{16}$ Normality of the retinal NFL four to six weeks after surgery portends recovery after decompression of the chiasm.

Prechiasmatic or chiasmatic field defects may present with atypical nerve fibre bundle defects that mimic disease of the optic nerve head. We have encountered several such defects at the Neuro-Ophthalmology Unit, Toronto Western Hospital. The following case is an example.

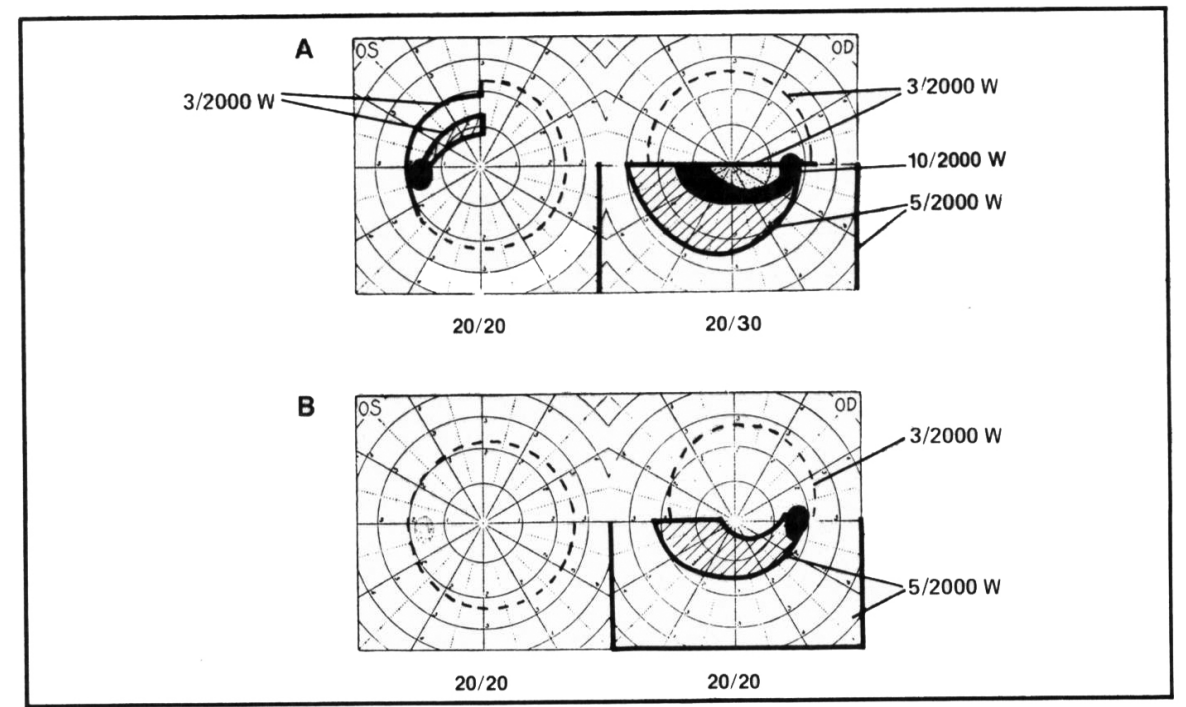

Figure 3 - Visual fields in a patient with a pituitary adenoma shows an arcuate hemianopic defect in the upper temporal field of the left eye, and an inferior arcuate defect in the right eye (A). After transphenoidal removal of the tumour, the field of the left eye is normal, and the defect in the right eye is improved (B). 
A 54 year old man complained of progressive minor dimming of vision in the right eye for two years. He had no symptoms of endocrine dysfunction. Examination showed that his visual acuity was reduced to $20 / 30$ in the right eye and normal in the left eye. He had a right RAPD. Colour vision was impaired in the right eye (10/15 Ishihara plates) and normal in the left. The left optic disc was normal but the right disc showed segmental pallor of the upper pole. Visual field examination revealed an inferior arcuate-altitudinal defect in the right eye (Figure $3 A$ ). In the left eye there was a subtle upper temporal step and an upper temporal arcuate defect extending from the blind spot to the vertical meridian. Skull $x$-rays showed sellar enlargement, erosion of its floor, undermining of anterior clinoid processes and demineralization of the dorsum sella. Radiography showed an intrasellar mass with anteronasal and suprasellar extension. Tests of endocrine function were normal. After carotid angiography excluded a supraclinoid aneurysm, a pituitary adenoma was removed by the transphenoidal route. One week after surgery his visual acuity had returned to normal in the right eye. The inferior field defect was improved in the right eye (Figure 3B) and the field of the left eye was normal.

The occurrence of a hemianopic arcuate defect in the left eye provides evidence that the nerve fibre organization present at the optic disc is preserved into the optic chiasm. ${ }^{17}$ The inferior altitudinal-arcuate defect in the right eye resembled that resulting from ischemic optic neuropathy or glaucoma. Normal intraocular pressures, absence of pathological disc cupping, and improvement of the field defect after removal of the pituitary adenoma precluded those causes. The tempo of slowly progressing monocular, or binocular visual loss demands neuroradiologic studies to exclude compressive optic neuropathy, regardless of the pattern of visual field loss.

\section{REFERENCES}

1. Hoyt WF, Meschel LG, Lessell S, et al. Malignant optic glioma of adulthood. Brain 1973; 96:121-132.

2. Jefferson G. On compression and invasion of the optic nerves and chiasm by neighbouring gliomas. Trans Ophthalmol Soc UK $1945 ; 65: 262-304$.
3. Rutka JD, Sharpe JA, Resch L, et al. Compressive optic neuropathy and ependymoma of the third ventricle. J Clin Neuroophthalmol 1985 (in press).

4. Knight CL, Hoyt WF, Wilson CB. Syndrome of incipient prechiasmal optic nerve compression. Arch Ophthalmol 1972; 87:1-11.

5. Rosenstein $\mathbf{J}$ and Symon L. Surgical management of suprasellar meningioma. Part 2: Prognosis for visual function following craniotomy. J Neurosurg 1984; 61:642-648.

6. Wilson $P$ and Falconer MA. Patterns of visual failure with pituitary adenomas: clinical and radiological correlates. $\mathrm{Br} \mathrm{J}$ Ophthalmol 1968; 52:94-110.

7. Thompson HS, Montague P, Cox TA, et al. The relationship between visual acuity, pupillary defect, and visual field loss. Amer J Ophthalmol 1982; 93:681-688.

8. Sharpe JA. The pupils. Amer Academy of Neurology. Neuroophthalmology Course 1984; 244:75-88.

9. Bell RA and Thompson HS. Relative afferent pupillary defects in optic tract hemianopias. Am J Ophthalmol 1978; 85:538-540.

10. Trobe JD, Acosta P, Krischer JP, et al. Confrontation visual field techniques in detection of anterior visual pathway lesions. Ann Neurol 1981; 10:28-34.

11. Hoyt WF. Correlative functional anatomy of the optic chiasm. Clinical Neurosurg 1969; 17:189-208.

12. Frisèn $L$. The cornerstones of perimetric strategy. In: Thompson HS, ed. Topics in Neuro-Ophthalmology. Baltimore: Williams \& Wilkins, 1979: 5-19.

13. McDonald WI. The symptomatology of tumours of the anterior visual pathways. The JL Silversides Lecture. Can J Neurol Sciences 1982; $9: 381-390$.

14. Jacobson SG, Eames RA, McDonald WI. Optic nerve fibre lesions in adult cats: patterns of recovery of spatial vision. Exp Brain Res 1979; 36:491-508.

15. White OB and Sharpe JA. Retinal nerve fibre atrophy in compression of the chiasm: a prognostic sign. Can J Neurol Sciences $1980 ; 7: 327$.

16. Lundstrom $M$ and Frisen L. Atrophy of optic nerve fibres in compression of the chiasm. Acta Ophthalmol 1976; 54:623-640.

17. Trobe JD. Chromophobe adenoma presenting with a hemianopic temporal arcuate scotoma. Amer J Ophthalmol 1974;77:388-392. 